\title{
Seroepidemiology of parapoxvirus infections in captive and free-ranging California sea lions Zalophus californianus
}

\author{
Hendrik H. Nollens ${ }^{1, *}$, Frances M. D. Gulland ${ }^{3}$, Jorge A. Hernandez ${ }^{2}$, \\ Richard C. Condit ${ }^{4}$, Paul A. Klein ${ }^{5}$, Michael T. Walsh ${ }^{6}$, Elliott R. Jacobson ${ }^{1}$ \\ ${ }^{1}$ Marine Mammal Health Program and Department of Small Animal Clinical Sciences, and ${ }^{2}$ Department of Large Animal \\ Clinical Sciences, College of Veterinary Medicine, University of Florida, PO Box 100126, Gainesville, Florida 32610, USA \\ ${ }^{3}$ The Marine Mammal Center, 1065 Fort Cronkhite, Sausalito, California 94965, USA \\ ${ }^{4}$ Department of Molecular Genetics and Microbiology, and ${ }^{5}$ Department of Pathology, Immunology and Laboratory \\ Medicine, College of Medicine, University of Florida, PO Box 100275, Gainesville, Florida 32610, USA \\ ${ }^{6}$ SeaWorld Orlando, 7007 SeaWorld Drive, Orlando, Florida 32821, USA
}

\begin{abstract}
Cutaneous nodular lesions caused by parapoxvirus infections are commonly observed in stranded pinnipeds following their arrival at rehabilitation facilities. An indirect enzyme-linked immunosorbent assay (ELISA) was developed and validated to determine exposure to parapoxviruses in California sea lions Zalophus californianus in captivity and in the wild. The diagnostic performance of this assay was evaluated using receiver-operating characteristic analysis. At a selected cut-off value, the calculated sensitivity was $100 \%(95 \% \mathrm{CI}=86$ to $100 \%)$ and the specificity was $100 \%(95 \% \mathrm{CI}=87$ to $100 \%)$. Analysis of sera collected from 26 affected sea lions during various stages of the disease revealed anti-parapoxvirus antibodies in all affected sea lions prior to the development of cutaneous pox lesions. This indicated that previous exposure to a parapoxvirus does not confer protection against clinical disease. In at least 7 cases, exposure to the virus occurred during hospitalization. Analysis of paired sera from 74 unaffected sea lions indicated subclinical infections in at least 3 animals. Finally, the prevalence of anti-parapoxviral antibodies in 761 free-ranging California sea lions captured and tested was $91 \%$ (95\% CI = 89 to $93 \%$ ). This indicated that infection with a parapoxvirus is a common occurrence in the wild and that the release of captive sea lions infected with parapoxvirus into the wild should not increase the risk of a parapoxvirus outbreak in free-ranging sea lions.
\end{abstract}

KEY WORDS: Zalophus californianus - California sea lion · Pinniped · Pox · Poxvirus · Antibody · ELISA $\cdot$ Serology

Resale or republication not permitted without written consent of the publisher

\section{INTRODUCTION}

The viral family Poxviridae includes several viruses of veterinary and medical importance. Poxviruses affect domestic and wild mammals, reptiles and birds. In humans, the most notorious member, variola virus, causes smallpox (Moss 1996, Murphy et al. 1999). Aquatic mammals also are susceptible to poxvirus infections. The susceptibility of pinnipeds to poxvirus infections was first suspected in 1969, when a 1 yr old sea lion was presented with pox-like lesions (Wilson et al. 1969). The presence of a poxvirus has since been confirmed in harbor seals Phoca vitulina (Wilson et al. 1972), northern fur seals Callorhinus ursinus (Hadlow et al. 1980), gray seals Halichoerus grypus (Hicks \& Worthy 1987), northern elephant seals Mirounga angustirostris (Hastings et al. 1989), South American sea lions Otaria flavescens (Wilson \& Poglayen- 
Neuwall 1971) and, more recently, in California sea lions Zalophus californianus (Nollens et al. 2006).

Pox lesions in pinnipeds are seen as raised cutaneous nodules, reaching up to $3 \mathrm{~cm}$ in diameter (Hastings et al. 1989), which may ulcerate and suppurate. Pox lesions develop primarily on the head and neck, but the thorax, abdomen and flippers can be affected. In severe cases, the body of affected animals can be covered by up to several hundred nodules (Wilson \& Poglayen-Neuwall 1971). Histologically, the pox nodules are formed by epithelial hyperplasia and hypertrophy, with epithelial cells often containing large, eosinophilic, intracytoplasmic inclusions consisting of pox virions (Hadlow et al. 1980). Mortality in captive pinnipeds is typically low, except in cases where nodules develop on the eyes or in the oral cavity or nostrils, where the infection impairs feeding or respiration. However, the morbidity of poxvirus infections is typically high, especially in young animals. Captive pinnipeds with pox lesions are unsuitable for display, and secondary parapoxvirus infections are likely to negatively affect the physiology, prognosis and length of hospitalization of animals in rehabilitation centers. The seal poxvirus is also a zoonosis, and is therefore of concern to animal care staff (Hicks \& Worthy 1987).

Several early reports are available on the light microscopic and electron microscopic appearance of the pox lesions in different species of pinnipeds (reviewed in Muller et al. 2003). More recent studies have confirmed parapoxviruses as the etiologic agent of this disease (Osterhaus et al. 1990, 1994, Nollens et al. 2006). Previous knowledge on the epidemiology of poxvirus infections in sea lions is limited to 1 study conducted in hospitalized sea lions in a rehabilitation center in California (Nollens et al. 2005). In that study, readmission to a rehabilitation center, long duration of hospitalization and high hospital caseload were identified as risk factors that may predispose California sea lions to acquiring poxvirus infections during hospitalization. While this epidemiologic information is relevant for formulation, implementation and evaluation of infection control measures to reduce risk of nosocomial infections in hospitalized sea lions, the prevalence of subclinical poxvirus in free-ranging California sea lions is not known. Furthermore, no serological test for detection of anti-parapoxviral antibodies has been developed. Therefore, the objectives of the present study were to (1) develop and validate an enzyme-linked immunosorbent assay (ELISA) for detection of antibodies against poxvirus in California sea lions, (2) describe the antibody response of affected and unaffected sea lions to parapoxviruses during rehabilitation, and (3) estimate the seroprevalence of parapoxvirus infections in free-ranging California sea lions.

\section{MATERIALS AND METHODS}

Positive and negative reference serum samples. A panel of 24 positive and 26 negative reference samples was selected from the California sea lion Zalophus californianus serumbank at The Marine Mammal Center (TMMC) $\left(37^{\circ} 51^{\prime} \mathrm{N}, 122^{\circ} 31^{\prime} \mathrm{W}\right)$ to optimize and evaluate the diagnostic performance of the ELISA. The 24 positive reference sera were collected from 24 California sea lions that had been found stranded on the central California coast between 6 July 2002 and 19 September 2004 and were hospitalized in TMMC for rehabilitation. Poxvirus infections in California sea lions typically manifest as prominent dermal nodules, 1 to $3 \mathrm{~cm}$ in diameter, that occur on the head, neck, or flippers of the sea lions. The presence of these dermal pox lesions is pathognomonic for the presence of a poxvirus (Hastings et al. 1989). Sea lions with dermal pox lesions were classified as 'affected'. The 24 California sea lions developed poxvirus lesions between 1 and $87 \mathrm{~d}$ (median $=20$, min. = 1, $\max .=87$ ) after hospitalization in TMMC. One serum sample was collected from each of the 24 affected sea lions, on average $12 \mathrm{~d}$ after first clinical signs $($ FCS $)($ median $=3$, min. $=1$, $\max .=65)$. The negative reference sera were collected from 26 sea lion fetuses that were aborted between 5 July 1998 and 3 July 2003 by adult female California sea lions affected by domoic acid toxicosis. All sera were kept frozen at $-80^{\circ} \mathrm{C}$ until analysis.

ELISA procedure. Antigen production: A parapoxvirus of California sea lions (Sea Lion Poxvirus 1; SLPV-1) was previously isolated in our laboratory in early-passage California sea lion kidney cells (Nollens et al. 2006). Purified SLPV-1 was used as an antigen in the whole virus-based, indirect ELISA system. For purification, the virus was propagated in early-passage California sea lion kidney cells. When $>90 \%$ of the monolayer showed cytopathic effect, the cells and supernatants were harvested and freeze-thawed twice and the virus was purified as previously described (Nollens et al. 2006). Briefly, intracellular mature virions (IMV) were purified from the infected cell lysates by high-speed centrifugation through a $40 \%$ sucrose cushion followed by banding of the IMV on a 25 to $50 \%$ Na-diatrizoate density gradient. The virus was resuspended in $10 \mathrm{mM}$ Tris $(\mathrm{pH}$ 8.2) and stored at $-80^{\circ} \mathrm{C}$ until analysis. For use in the ELISA, the virus was thawed, sonicated for $3 \mathrm{~min}$ and inactivated in $2 \%$ paraformaldehyde for $30 \mathrm{~min}$ at approximately $22^{\circ} \mathrm{C}$. The protein concentration of the inactivated virus concentrate was determined using a modified Bradford assay for ELISA, after which the inactivated virus was diluted in phosphate-buffered saline (PBS) to the desired coating concentration. 
Selection of secondary detection reagent: The ability of a panel of alkaline-phosphatase-labeled secondary reagents $(\mathrm{N}=19$; Protein $\mathrm{G}$ [Zymed]; Protein A, goat anti-chicken whole IgG pAb, goat anti-mouse IgG Fab pAb, goat anti-mouse whole IgG pAb, goat antirat whole IgG pAb, goat anti-guinea pig Ig pAb, goat anti-rabbit whole IgG $\mathrm{pAb}$, goat anti-hamster IgG [heavy and light chain] pAb, rabbit anti-horse whole Ig pAb, rabbit anti-cow whole Ig pAb, rabbit anti-goat whole Ig pAb, donkey anti-sheep Ig pAb [Sigma]; goat anti-rabbit IgG Fab pAb, goat anti-rabbit IgG Fc pAb, donkey anti-rabbit IgG [heavy and light chain] pAb [Pierce]; rabbit anti-dolphin whole IgG [Bethyl Laboratories]; rabbit anti-dolphin whole IgG, rabbit anti-bat whole IgG [University of Florida]) to react with California sea lion immunoglobulins was evaluated using ELISA. Wells of a high protein-binding microplate (Nunc Maxisorp, Fisher Scientific) were coated with $50 \mu \mathrm{l}$ of whole California sea lion serum diluted 1:1000 in $1 \times$ PBS, and were left to adsorb overnight at $4^{\circ} \mathrm{C}$. After this and each subsequent step, all wells were washed 3 times with PBS/Az and $0.05 \%$ PBS-T using an automated microplate washer (BioTek Instruments). After washing, the wells were blocked with $1 \%$ bovine serum albumin (BSA; Roche Diagnostics), after which each of the 22 secondary reagents (diluted 1:2000 in $1 \%$ BSA in PBS with $0.02 \%$ azide [PBS/Az]) was applied to each of 2 wells. Each step of the ELISA was left to incubate with gentle agitation (Nutator; Adams, Fisher Scientific) for $1 \mathrm{~h}$ at approximately $22^{\circ} \mathrm{C}$. Finally, $1.0 \mathrm{mg} \mathrm{ml}^{-1}$ P-nitrophenyl phosphate (PNPP; Sigma) substrate was added, and the absorbance at $405 \mathrm{nM}$ $\left(\mathrm{OD}_{405}\right)$ was recorded after 30 min using a Spectramax 250 microplate reader (Molecular Devices). Of the 22 reagents tested, Protein G (Zymed), Protein A, goat anti-chicken Ig $\mathrm{pAb}$, goat anti-rabbit Ig $\mathrm{pAb}$, rabbit anti-horse Ig pAb, goat anti-guinea pig Ig pAb, rabbit anti-cow Ig pAb and donkey anti-sheep Ig pAb (Sigma) appeared to crossreact with California sea lion serum in ELISA format. The highest reactivity was observed using Protein A $\left(\mathrm{OD}_{405}=4.173\right)$, rabbit anticow Ig pAb $\left(\mathrm{OD}_{405}=4.100\right)$, donkey anti-sheep Ig pAb $\left(\mathrm{OD}_{405}=4.037\right)$ and Protein $\mathrm{G}\left(\mathrm{OD}_{405}=2.653\right)$.

Next, the specificity of Protein A, rabbit anti-cow Ig pAb, donkey anti-sheep Ig pAb and Protein G for immunoglobulins of California sea lions was evaluated by $\mathrm{Na}^{+}$dodecylsulphate polyacrylamide gel electrophoresis (SDS-PAGE). California sea lion serum, diluted 1:10 in PBS, was separated (45 min at $200 \mathrm{~V}$ ) by SDS-PAGE under denaturing conditions, with a precast $10 \%(\mathrm{w} / \mathrm{v})$ polyacrylamide bis-tris Nupage gel and morpholinepropanesulfonic acid (MOPS) running buffer (Invitrogen). Purified mouse and bovine IgG, diluted 1:10 in PBS, were included as reference sera. The protein fractions from all lanes were electrophoretically transferred
(60 min at $30 \mathrm{~V}$ ) to a nitrocellulose sheet (Invitrogen) using a Novex Western transfer apparatus. Tris-glycine buffer (Invitrogen) in 20\% methanol was used as the transfer buffer. After transfer, the nitrocellulose was blocked overnight using $5 \%$ nonfat dry milk in PBS/Az at approximately $22^{\circ} \mathrm{C}$. The nitrocellulose blot was washed with PBS-T and placed into a Fast BlotDeveloper (Pierce). A total of $900 \mu \mathrm{l}$ of each of the 4 secondary reagents was loaded into a channel each and was left to incubate for $60 \mathrm{~min}$ at approximately $22^{\circ} \mathrm{C}$ with gentle agitation (Nutator; Adams, Fisher Scientific). Rabbit anti-mouse IgG polyclonal antibody (pAb) and rabbit anti-bovine IgG pAb were loaded into the mouse and bovine IgG reference lanes. After washing 3 times with PBS-Az, the blot was developed with NBTBCIP (nitroblue tetrazolium-5-bromo-4-chloro-3 inolyphosphate $p$-toluidine) substrate following the manufacturer's instructions (Sigma). All 4 reagents reacted with a band comparable in size with the $\gamma$ heavy chain of mouse and bovine IgG (55 kDa). Overall, AP (alkaline phosphatase)-labeled Protein A appeared to have the highest affinity for immunoglobulins of California sea lions on ELISA and reacted strongly with a band of approximately $55 \mathrm{kDa}$ on the SDS-PAGE blot. Consequently Protein A was selected as the secondary detection reagent for the ELISA.

Optimization of ELISA parameters: Three randomly selected positive and 3 randomly selected negative reference serum samples were used to optimize the ELISA conditions. All assay parameters were varied

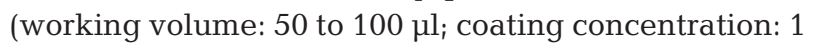
to $15 \mathrm{\mu g} \mathrm{ml}^{-1}$; California sea lion serum dilution: 1:20 to 1:2500; developing time: 15 to $60 \mathrm{~min}$ ), and the assay conditions with the highest ratio of the mean $\mathrm{OD}_{405}$ of positive reference serum samples $(\mathrm{N}=3)$ to the mean $\mathrm{OD}_{405}$ of negative reference serum samples $(\mathrm{N}=3)$ were selected. The conditions of the optimized ELISA protocol were as follows. Wells of high protein-binding microplate were coated with $50 \mu \mathrm{l}$ of inactivated whole virus (SLPV-1) at $2 \mu \mathrm{g} \mathrm{ml}^{-1}$ in PBS, and were left to adsorb overnight at $4^{\circ} \mathrm{C}$. After this and each subsequent step, all wells were washed 3 times with PBS/Az and $0.05 \%$ PBS-T using an automated microplate washer. After washing, all wells were blocked with $1 \%$ BSA in PBS/Az, after which the California sea lion sera were applied (1:500 in 1\% BSA in PBS/Az) to each of 2 wells. AP-labeled Protein A (1:2000 in 1\% BSA in $\mathrm{PBS} / \mathrm{Az}$ ) was applied as the secondary reagent for the detection of bound sea lion antibodies. Each step of the ELISA was left to incubate with gentle agitation (Nutator) for $1 \mathrm{~h}$ at approximately $22^{\circ} \mathrm{C}$. Finally, $1.0 \mathrm{mg} \mathrm{ml}^{-1}$ PNPP substrate was added. The $\mathrm{OD}_{405}$ was recorded 30 min after addition of the substrate using a Spectramax 250 microplate reader. To correct for variation between ELISA plates, the mean $\mathrm{OD}_{405}$ of each sample 
was divided by the $\mathrm{OD}_{405}$ of positive reference serum California Sea Lion 5814b.

Diagnostic performance of ELISA: The sensitivity (Se, proportion of affected California sea lions with positive test results), specificity (Sp, proportion of unaffected California sea lions with negative test results), positive predictive values (the fraction of California sea lions that test positive that have truly been exposed to poxviruses) and negative predictive values (the fraction of California sea lions that test negative that have truly not been exposed to poxviruses) of the ELISA were calculated at different cut-off points using MedCalc 4.15c software (F. Schoonjans). The selection of the cut-off point to identify highest performance (combination of high Se and high $\mathrm{Sp}$ ) was made by means of a receiver-operator characteristic (ROC) curve based on the corrected $\mathrm{OD}_{405}$ of the 24 positive and 26 negative reference samples using MedCalc 4.15c software.

Seroepidemiology of parapoxvirus infections. Captive sea lions: Hospitalized sea lions that developed dermal pox lesions during their hospitalization were classified as affected, whereas sea lions that did not develop dermal lesions were classified as 'unaffected'. To evaluate the antibody response of these affected and unaffected California sea lions to parapoxviruses during rehabilitation, 56 serum samples were collected opportunistically from 26 affected yearling and subadult California sea lions at TMMC in Sausalito, California. The 56 serum samples consisted of 20 initial samples (collected from 16 sea lions prior to FCS), 18 acute samples (collected from 18 sea lions on the first day of clinical signs) and 18 convalescent samples (collected from 15 sea lions $>1 \mathrm{~d}$ after FCS). On average 2.2 samples (median $=2$, $\min .=2$, $\max .=4$ ) were available for each affected sea lion. The 20 samples collected from the 16 affected sea lions prior to FCS were collected on average $22 \mathrm{~d}$ after admission (median = 19, min. $=1$, max. $=64$ ) and $25 \mathrm{~d}$ prior to FCS (median $=$ 17 , $\min .=1, \max .=85$ ). The 18 convalescent sera collected from the 15 affected sea lions were collected, on average, $22 \mathrm{~d}$ after FCS (median $=14, \min .=2$, max. = 65). A complete set of paired sera, consisting of at least 1 initial serum (prior to FCS) and at least 1 convalescent serum sample ( $\geq 1 \mathrm{~d}$ after FCS), was available for 8 sea lions. The initial $(\mathrm{N}=10)$ and convalescent $(\mathrm{N}=8)$ sera were collected from these 8 sea lions on average $24 \mathrm{~d}$ (median $=16$, min. $=1, \max .=69$ ) prior to FCS and $17 \mathrm{~d}$ (median $=14$, min. $=3$, max. $=44$ ) after FCS.

Additionally, 164 serum samples were collected opportunistically from 74 unaffected yearling, subadult and adult California sea lions, starting with a sample obtained within $6 \mathrm{~d}$ of admission and ending with samples just prior to release. On average, $2.2 \mathrm{sam}-$ ples $($ median $=2$, $\min .=2$, $\max .=5$ ) were available for each unaffected sea lion.
All California sea lions included in this study had been found stranded on the central California coast between 27 January 2002 and 19 September 2004 and were hospitalized in TMMC for rehabilitation. The presence of anti-parapoxviral antibodies in all serum samples was determined using indirect ELISA as described above. Reference Sera CSL5814b and F5200 were included on each ELISA plate as positive and negative controls, respectively. Each serum sample was analyzed in duplicate, and the corrected $\mathrm{OD}_{405}$ was calculated for each sample as described above. The sea lion age classes were defined as follows: pup, $<1 \mathrm{yr}$; yearling, 1 to $<2 \mathrm{yr}$; subadult male, 2 to $8 \mathrm{yr}$; subadult female, 2 to $5 \mathrm{yr}$; adult male, $>8 \mathrm{yr}$; and adult female, $>5$ yr.

Free-ranging sea lions: A total of 551 serum samples from 67 weaned (6 to 12 mo old) pups, 130 yearlings ( 1 to 2 yr old), 188 juveniles/subadults and 166 adult California sea lions were selected from the serum bank at TMMC (Table 1). Only serum samples that were collected within $6 \mathrm{~d}$ of admission to TMMC and from animals that had not previously been admitted to a rehabilitation center were included in the survey. Sea lions that had been in captivity $<6 \mathrm{~d}$ were considered serologically representative of the free-ranging population. All 551 California sea lions had been found stranded on the central California coast between 3 January 2000 and 24 August 2004 and were hospitalized in TMMC for rehabilitation. In addition, a second group of serum samples from 150 pre-weanling pups (2 to 4 mo old) and 60 adult male California sea lions from ongoing population monitoring programs were selected and tested for poxvirus antibodies. The sera from the preweanling California sea lions were collected on San Miguel Island, California ( $\left.34^{\circ} 2^{\prime} \mathrm{N}, 120^{\circ} 26^{\prime} \mathrm{W}\right)$ during September 2001, 2002 and 2003 and during October 2000 and 2004 (Table 2). The sera from adult male sea lions were collected in Shilshole Bay, Washington $\left(47^{\circ} 41^{\prime} \mathrm{N}, 122^{\circ} 24^{\prime} \mathrm{W}\right)$ during April and October 2001 and May 2003. Forty-two (47\%) of the adult males were sampled just prior to the annual breeding season (April to June). Seventy-seven (56\%) of the adult female sea lions were sampled during their hospitalization at TMMC, shortly after the breeding season (July to September), whereas only $24(18 \%)$ of the adult females were sampled just prior to the breeding season (April to June) (Tables 1 \& 2). Each serum sample was analyzed in duplicate, and the corrected $\mathrm{OD}_{405}$ was calculated for each sample as described above.

Data analysis. Prevalence of exposure to antiparapoxviral antibodies was calculated as the number of sea lions classified as seropositive divided by the number of sampled and tested sea lions. Ninety-five percent confidence intervals $(95 \% \mathrm{CI})$ were estimated to describe the precision of the point estimate (ob- 
Table 1. Zalophus californianus. Sample size (N), number of California sea lions with anti-parapoxviral antibodies (positive), antibody prevalence (\%) and $95 \%$ confidence interval ( $95 \% \mathrm{CI})$ for each category of gender, age, sample location (origin) and month of sampling (month)

\begin{tabular}{|c|c|c|c|c|c|}
\hline & $\mathrm{N}$ & Positive & $\begin{array}{c}\text { Prevalence } \\
(\%)\end{array}$ & $95 \% \mathrm{CI}$ & $\mathrm{p}$ \\
\hline Gender & & & & & 0.25 \\
\hline Female & 342 & 307 & 90 & $87-93$ & \\
\hline Male & 419 & 386 & 92 & $89-95$ & \\
\hline Age & & & & & $<0.01$ \\
\hline Pre-weanling pup (2-4 mo) & 150 & 147 & 98 & $95-100$ & \\
\hline Weanling pup $(6-12 \mathrm{mo})$ & 67 & 62 & 92 & $86-99$ & \\
\hline Yearling $(1-2$ yr $)$ & 130 & 121 & 93 & $89-97$ & \\
\hline Juvenile/Subadult & 188 & 178 & 94 & $91-98$ & \\
\hline Adult & 226 & 185 & 81 & $77-87$ & \\
\hline Origin & & & & & $<0.01$ \\
\hline Shilshole Bay & 56 & 40 & 71 & $60-83$ & \\
\hline Mendocino, Sonoma, & & & & & \\
\hline $\begin{array}{l}\text { Marin Co. } \\
\text { Alameda. Contra Costa. }\end{array}$ & 50 & 45 & 90 & $82-98$ & \\
\hline San Francisco, San Mateo Co. & 81 & 76 & 93 & $88-99$ & \\
\hline Santa Cruz Co. & 97 & 87 & 89 & $83-96$ & \\
\hline Monterey Co. & 184 & 175 & 95 & $92-98$ & \\
\hline $\begin{array}{l}\text { San Luis Obispo, Santa } \\
\text { Barbara, Los Angeles Co. }\end{array}$ & 139 & 121 & 87 & $81-93$ & \\
\hline San Miguel Island & 150 & 147 & 98 & $96-100$ & \\
\hline Month & & & & & $<0.01$ \\
\hline Jul-Sep & 342 & 314 & 92 & $89-95$ & \\
\hline Oct-Dec & 180 & 172 & 96 & $93-99$ & \\
\hline Jan-Mar & 26 & 20 & 77 & $61-93$ & \\
\hline Apr-Jun & 213 & 187 & 88 & $84-92$ & \\
\hline Total & 761 & 693 & 91 & $89-93$ & \\
\hline
\end{tabular}

Table 2. Zalophus californianus. Sample size (N), number of California sea lions with anti-parapoxviral antibodies (positive) and antibody prevalence $(\%$, in parentheses) per month of sampling and age category sea lions. na: no California sea lions belonging to that age category were available during these months

\begin{tabular}{|c|c|c|c|c|c|c|c|c|}
\hline \multirow[t]{2}{*}{ Age/Gender } & \multicolumn{2}{|c|}{ Jul-Sep } & \multicolumn{2}{|c|}{ Oct-Dec } & \multicolumn{2}{|c|}{ Jan-Mar } & \multicolumn{2}{|c|}{ Apr-Jun } \\
\hline & $\mathrm{N}$ & Positive & $\mathrm{N}$ & Positive & $\mathrm{N}$ & Positive & $\mathrm{N}$ & Positive \\
\hline Adult male & 12 & $9(75)$ & 30 & $25(83)$ & 5 & $4(80)$ & 42 & $29(69)$ \\
\hline Adult female & 77 & 67 (87) & 30 & $29(97)$ & 6 & $3(50)$ & 24 & $19(79)$ \\
\hline Adult & 89 & $76(85)$ & 60 & $54(90)$ & 11 & $7(64)$ & 66 & $48(73)$ \\
\hline $\begin{array}{l}\text { Juvenile/ } \\
\text { Subadult }\end{array}$ & 92 & $85(92)$ & 61 & $61(100)$ & 8 & $8(100)$ & 27 & $24(89)$ \\
\hline $\begin{array}{l}\text { Yearling } \\
\quad(1-2 \text { yr })\end{array}$ & 54 & $47(87)$ & 16 & $16(100)$ & 5 & $4(80)$ & 55 & 54 (98) \\
\hline $\begin{array}{l}\text { Weanling } \\
\qquad(6-12 \mathrm{mo})\end{array}$ & na & na & na & na & 2 & $1(50)$ & 65 & $61(94)$ \\
\hline $\begin{array}{l}\text { Pre-weanling } \\
(2-4 \text { mo }) \\
\text { Overall }\end{array}$ & 107 & 106 (99) & 43 & $41(60)$ & na & na & na & na \\
\hline prevalence & 342 & 314 (92) & 180 & $172(96)$ & 26 & $20(77)$ & 213 & $187(88)$ \\
\hline
\end{tabular}

served seroprevalence). Using a univariable analysis approach, seroprevalence estimates were compared between males and females, age groups, origin of sea lions and months of sampling by using a chi-squared test. Finally, a logistic regression model was used to compare prevalence estimates after controlling for the potentially confounding effects of gender, age, origin and month of sampling. Interaction effects between these variables were not examined. A p-value of $<0.05$ was used to establish statistical significance.

\section{RESULTS}

\section{Diagnostic performance of ELISA}

Based on the ROC analysis of the corrected $\mathrm{OD}_{405}$ of the positive and negative reference sera, a positive: negative cut-off value of 0.10 was selected. California sea lion Zalophus californianus serum samples for which the corrected $\mathrm{OD}_{405}$ was $\leq 0.10$ were considered to have no antibodies against SLPV-1 (negative). Samples for which the corrected $\mathrm{OD}_{405}$ was $>0.10$ were considered to contain antibodies against SLPV-1 (positive or exposed), whereas samples for which the corrected $\mathrm{OD}_{405}$ was $\leq 0.10$ were considered not to contain detectable antibodies against SLPV-1 (negative or unexposed). Using this cut-off point, the Se was $100 \% \quad(95 \%$ CI $=86$ to $100 \%$ ) and the Sp was $100 \%$ (95\% $\mathrm{CI}=87$ to $100 \%)$. The calculated area under the curve (AUC) was 1.0 (95\% $\mathrm{CI}=0.92$ to 1.00 ), indicating that the test accurately identified all affected and unaffected California sea lions used in the evaluation. Based on the lower $95 \%$ confidence limits of the sensitivity and specificity and based on a $91 \%$ prevalence of parapoxvirus antibodies in California sea lions, the predictive values for a positive and a negative result were 98 and $39 \%$, respectively. A frequency histogram of all corrected $\mathrm{OD}_{405}$ showed a bimodal distribution of the ELISA readouts (Fig. 1). A first peak (left peak) corresponded with the negative or unexposed sample population, including the 26 negative reference sera. A skewed, bell-shaped distribution curve (right peak) corresponded with the positive or exposed sample population, including the selected 24 positive reference sera (Fig. 1). 


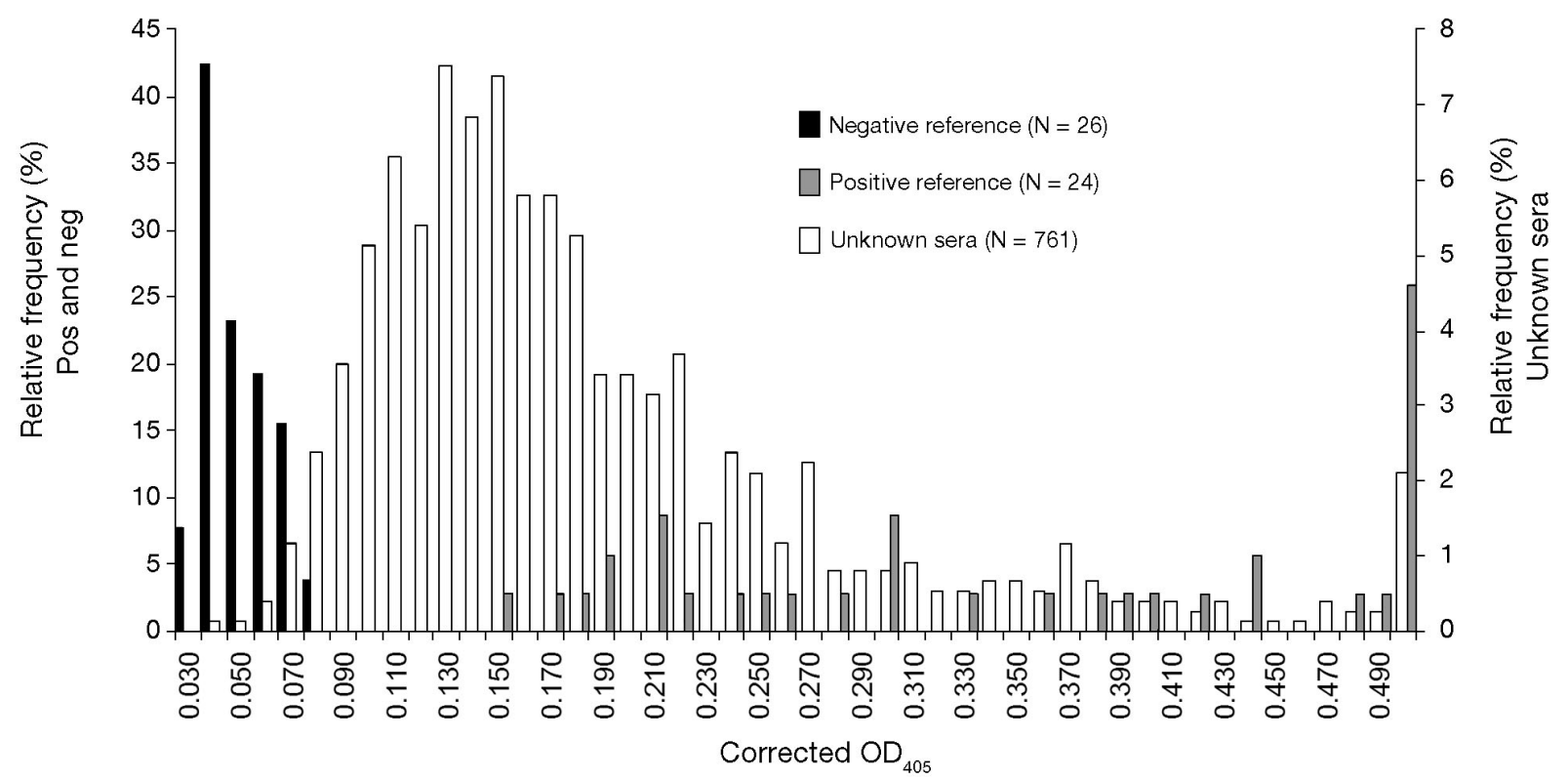

Fig. 1. Zalophus californianus. Frequency distribution of anti-parapoxviral antibody levels (expressed as corrected $\mathrm{OD}_{405}$ ), showing the bimodal distribution of antibody levels in California sea lions. Frequencies of antibody levels of positive and negative reference samples are plotted against the left $y$-axis. Frequencies of antibody levels of the unknown samples are plotted against the right $y$-axis

\section{Seroepidemiology of parapoxvirus infections}

\section{Captive sea lions}

A rise in circulating anti-parapoxviral antibodies was observed in all sea lions $(\mathrm{N}=8)$ for which at least 1 initial serum (collected prior to FCS) and at least 1 convalescent serum sample ( $\geq 1 \mathrm{~d}$ after FCS) was available. The intensity and the time of onset of the humoral immune response in these 8 animals varied, but a rise in circulating antibodies was detectable as early as $2 \mathrm{~d}$ before FCS in 3 sea lions. The rise in circulating antibodies was detectable in all convalescent sera collected $>1 \mathrm{~d}$ after FCS. On average and compared to the corresponding initial serum sample, a 1.8-fold increase in circulating antibodies was observed in sera collected from sea lions on the first day of clinical signs $(\mathrm{N}=10$ sea lions; $\bar{x}=1.8$-fold increase, $\mathrm{SD}=0.6$, min. $=$ 1.2 , max. $=3.0$ ). On average and compared to the corresponding initial serum sample, a 3.6-fold increase in the circulating antibody level was observed in all convalescent sera collected from sea lions $>1 \mathrm{~d}$ after FCS $(\mathrm{N}=8$ sea lions; $\bar{x}=3.6$-fold increase, $\mathrm{SD}=2.3$, min. $=$ 1.7, $\max .=7.6$ ).

The corrected $\mathrm{OD}_{405}$ values of all serum samples $(\mathrm{N}=$ 20) collected from affected California sea lions prior to developing pox lesions were $>0.10$ and were considered positive. Compared to sera collected upon admission, the level of circulating antibodies in 2 affected California sea lions had not yet increased at 24 and $39 \mathrm{~d}$ after admission to the hospital. These 2 animals developed clinical pox disease 70 and $58 \mathrm{~d}$, respectively, after admission to the hospital. Subsequently, a 2- to 3-fold increase in the level of circulating antibodies was observed in sera collected on Days 73 and 75, respectively, of hospitalization.

The corrected $\mathrm{OD}_{405}$ values of 63 (85\%) serum samples collected from the 74 unaffected California sea lions upon admission were $>0.10$ and were considered positive. Of the 74 unaffected sea lions, $5(7 \%)$ sea lions also had 3.6-fold increased levels of circulating antibodies $(\bar{x}=4.3$-fold increase, $\mathrm{SD}=0.7, \mathrm{~min} .=3.6$, max. $=5.0$ ) prior to release in comparison to at admission. Of these 5 sea lions, 3 were maintained at the rehabilitation center for 31,32 and $88 \mathrm{~d}$ after the rise in circulating antibodies was first detected, and no pox lesions were observed.

Free-ranging sea lions

A total of 761 California sea lions were included in the survey (Tables $1 \& 2$ ). The sample consisted of 419 males (55\%) and 342 females (45\%). Overall, the seroprevalence of anti-parapoxviral antibodies in the sampled and tested population of free-ranging California sea lions was $91 \%(95 \% \mathrm{CI}=89$ to $93 \%)$. The prevalence of seropositive sea lions was not different between females (92\%) and males (89\%) (Table 1). The proportion of seropositive adult male sea lions $(75 \%)$ was higher than the proportion of seropositive adult females $(86 \%)$, whereas the proportion of 
seropositive female sea lions was lower than that of males in all other age categories. The prevalence of seropositive sea lions was lower in animals from Shilshole Bay, Washington (71\%), than that in animals at any other location. In the univariable analysis (Table 1), seroprevalence was significantly different within age groups, origins and months of sampling $(\mathrm{p}<$ 0.05). In the multivariable analysis (Table 3), using logistic regression, the odds of exposure to parapoxviruses were higher in males, non-adult sea lions, sea lions from areas other than Shilhole Bay, and sea lions captured during October to December. No adjusted odds ratio (OR) was calculated for the location San Miguel Island, as the factor San Miguel Island was too highly correlated with other independent variables (age, month). The Hosmer-Lemeshow goodness-of-fit statistic for the logistic regression model was 10.04, with $\mathrm{df}=8$ and $\mathrm{p}=0.26$.

\section{DISCUSSION}

Our study results indicate that the newly developed ELISA test is a useful tool for the serologic diagnosis of poxvirus infections in California sea lions Zalophus californianus. The area under the ROC curve was 1.0, indicating that the ELISA is highly accurate. The ROC curve is a plot of the Se against the Sp of a given test and, as a result, the AUC is a measure of overall performance of a diagnostic test at multiple cut-off points (Greiner et al. 2003). The AUC values ranged between 0 and 1, with 1 representing a hypothetically perfect test (i.e. $100 \%$ sensitive, $100 \%$ specific). An AUC value of 0.5 indicates that the test is not informative, no better than a coin toss. When a ROC analysis was applied to the ELISA for the detection of antiparapoxviral antibodies in sea lions, a cut-off point of 0.10 was associated with a test Se and Sp of $100 \%$. The lower and upper limits of the $95 \%$ confidence intervals for sensitivity and specificity were 86 to $100 \%$ and 87 to $100 \%$, respectively, indicating that the precision of the calculated point estimates for both parameters was low, because our sample size was limited to 26 affected California sea lions and 26 unaffected sea lions; therefore, our study results must be interpreted with caution.
While the sensitivity and specificity are important parameters used to measure the accuracy of a diagnostic test, in the field, clinicians and wildlife managers are interested in knowing if a sea lion that tests positively to a serologic test is indeed exposed, or if a negative test is indicative of absence of exposure. These test characteristics are known as positive and negative predictive values, respectively, and they are influenced by disease prevalence. For example, based on an observed disease prevalence of $91 \%$ and a test sensitivity of $86 \%$ and a test specificity of $87 \%$, the positive and negative predictive values are 99 and 39\%, respectively. If this ELISA test were used in a subpopulation of sea lions where the observed disease prevalence was $50 \%$, the positive predictive value would decrease from 99 to $87 \%$ and the negative predictive value would increase from 39 to $86 \%$, respectively (MedCalc 4.15c).

In the present study we observed that the onset and the intensity of the humoral response of California sea lions to parapoxviruses were variable, but a rise in the level of antibodies was detectable in all California sea lions with clinical signs. In some cases, anti-parapoxviral antibodies were detected even before clinical signs were first observed. These findings are very

Table 3. Zalophus californianus. Logistic regression analysis. Adjusted odds ratio (OR), 95\% confidence interval (95\% CI) of exposure to parapoxvirus in California sea lions by gender, age, sample location (origin) and month of sampling (month). na: no California sea lions belonging to that age category were available during these months; nd: not determined (San Miguel Island was too highly correlated with other independent variables)

\begin{tabular}{|lccc|}
\hline & OR & $95 \%$ CI & $\mathrm{p}$ \\
\hline Gender & & & \\
Female & 1.00 & Reference & na \\
Male & 1.94 & $0.94-3.99$ & 0.07 \\
Age & & & \\
Pre-weanling pup (2-4 mo) & 1.00 & Reference & na \\
Weanling pup (6-12 mo) & 0.04 & $0.01-0.32$ & $<0.01$ \\
Yearling (1-2 yr) & 0.04 & $0.01-0.27$ & $<0.01$ \\
Juvenile/Subadult & 0.05 & $0.01-0.31$ & $<0.01$ \\
Adult & 0.03 & $0.01-0.13$ & $<0.01$ \\
Origin & & & \\
Shilshole Bay & 1.00 & Reference & na \\
Mendocino, Sonoma, Marin Co. & 3.54 & $0.92-13.66$ & 0.06 \\
Alameda, Contra Costa, & & & \\
San Francisco, San Mateo Co. & 6.41 & $1.74-23.62$ & $<0.01$ \\
Santa Cruz Co. & 4.66 & $1.49-14.61$ & $<0.01$ \\
Monterey Co. & 9.31 & $2.81-30.80$ & $<0.01$ \\
San Luis Obispo, Santa Barbara, & & & \\
Los Angeles Co. & 5.28 & $1.71-16.30$ & $<0.01$ \\
San Miguel Island & nd & nd & nd \\
Month & & & \\
Jul-Sep & 1.00 & Reference & na \\
Oct-Dec & 2.78 & $1.14-6.79$ & 0.02 \\
Jan-Mar & 0.45 & $0.15-1.36$ & 0.15 \\
Apr-Jun & 1.28 & $0.59-2.76$ & 0.53 \\
\hline
\end{tabular}


similar to the serologic observations of orf virus infections (the protypal parapoxvirus, also known as scabby mouth, contagious ecthyma) in sheep. The onset and intensity of the antibody response is variable, an antibody response is present in all cases and, above all, the appearance of antibodies coincides with the appearance of FCS (Dales \& Pogo 1981, Haig et al. 1997). Because of the high similarity between the anti-parapoxviral antibody dynamics of sheep and sea lions, it is likely that the length of the incubation period (i.e. the period between infection and FCS) is also similar. Based on experimental transmission studies, the incubation period of orf virus in sheep was determined to be approximately $7 \mathrm{~d}$ (Dales \& Pogo 1981, Haig et al. 1997). This suggests that the incubation period of parapoxvirus infections in California sea lions may be approximately $7 \mathrm{~d}$ as well.

Previous exposure of California sea lions to parapoxviruses does not necessarily protect against reinfection. All serum samples that were collected prior to clinical disease were seropositive and indicated prior exposure to a parapoxvirus. Similarly, the acquired immunity of sheep to parapoxviruses is short-lived and reinfection can occur (Haig et al. 1997). The mechanism behind this weak acquired protection of sheep is poorly understood, but the characteristic localized nature of a parapoxvirus infection may be in part responsible for this. Parapoxviruses typically do not cause a secondary, generalized viremia. If infections are acute and restricted to epidermal cells, the immune response may provide less protection. Localized infections may also go undetected for a longer time by the immune system and pre-existing immunity may therefore have a limited effect (Haig et al. 1997). Conversely, some studies have suggested that parapoxviruses do cause a secondary viremia, but this remains unconfirmed (Iketani et al. 2002). Regardless of the mechanism, the inability of the sea lions to be protected following exposure to parapoxviruses suggests that the usefulness of a vaccine may be as ambiguous as orf virus vaccines are in sheep. The efficacy of parapoxvirus vaccines for sheep is disputed, as in some cases they fail to confer protection against a challenge infection and in some cases even against a homologous virus (Buddle et al. 1984, Pye 1990). Vaccine strain differences, adaptation of the vaccine virus to cell culture and the antigenic diversity of wild orf virus strains have been suggested as possible causes for vaccination failures (Buddle et al. 1984, Pye 1990). However, a potent anamnestic immune response of sheep to orf virus reinfection has been reported (Haig et al. 1997). This anamnestic response does leave lambs susceptible to a second infection, but the lesions are smaller and heal more rapidly (Nettleton et al. 1996). We do not know if the clinical signs on sea lions become less severe as the animals are repeatedly infected.

Two affected and 5 unaffected sea lions were exposed to a parapoxvirus and developed antiparapoxviral antibodies during their hospitalization. Likewise, the appearance of clinical signs after $60 \mathrm{~d}$ or more does indicate that the infection was acquired during hospitalization, as previous estimates of incubation period range between 2 and $5 \mathrm{wk}$ (Hastings et al. 1989). No known poxvirus has the ability to establish a latent infection, and reactivation of a previous infection is therefore not likely. As a result, it may be possible to reduce the incidence of poxvirus infections in pinnipeds in rehabilitation centers by using prophylactic measures. These measures should be aimed at minimizing the direct and indirect contact between animals, both during the incubation period and during clinical disease. We observed a rise in circulating antibodies in 5 unaffected animals as well. Of these 5 sea lions, 3 were maintained at the rehabilitation center for $>1$ mo after the rise in circulating antibodies was first detected, and no pox lesions were observed. This indicates that subclinical parapoxvirus infections can occur in California sea lions, suggesting that prophylactic measures should include minimizing all contact between unaffected animals as well. Since parapoxviruses have the ability to persist in the environment for months to years (Haig et al. 1997) and are resistant to desiccation, thorough cleaning of the hospital pens is advised. Effective cleaning practices should consist of the thorough scrubbing of the pens to remove all organic material, followed by bleaching or washing with detergents with known virucidal activity.

A total of 693 of $761(91 \%)$ of the sampled and tested study population of California sea lions tested positive to poxvirus antibodies. This high seroprevalence is likely a reflection of the typical highly infectious nature of poxviruses and the high rate of contact amongst wild California sea lions (Odell 1975). Each spring all reproductively active animals congregate in the California Channel Islands (e.g. San Miguel Island, California) for pupping and subsequent breeding (Odell 1975). The exact reasons for the apparent lower antibody prevalence in adult males are unclear. Adult male California sea lions occupy separate bachelor colonies near the northern end of the range of their species (e.g. Shilshole Bay, Washington), but male California sea lions return to their bachelor colonies shortly after breeding and have little contact with pup and yearling animals. If, in free-ranging animals, the virus circulates particularly among young sea lions, adult males could be less frequently exposed. Alternatively, the lower antibody prevalence in adult males could be accounted for by a temporal bias in the sample set used for this serosurvey. Most adult male sea lions (47\%) were sampled just 
prior to the breeding season, whereas the majority of adult female sea lions (56\%) was sampled shortly after the breeding season (Table 2). If the virus circulates during the annual breeding congregation and if the antibodies are short lived, antibody levels of adult male sea lions may have dropped below the detection limit by the time of sampling. Unfortunately, due to the low number of samples collected during some parts of the year, our sample set does not allow for further exploration of a seasonal effect on antibody prevalence. Ideally, a randomly selected sample set with stratification for age, gender, season and location should have been employed in this serosurvey. In the absence of such a stratified sample, a convenience sample was used, and inherent biases can therefore not be discounted. Also, because our sample set is not weighted to reflect the population structure of California sea lions, the overall seroprevalence estimate needs to be interpreted with caution. Although our data do indicate that the prevalence of anti-parapoxviral antibodies in free-ranging California sea lions is high, the exact seroprevalence estimate of $91 \%$ may not apply to the free-ranging California sea lion population.

The high seroprevalence in nursing sea lion pups (98 to $100 \%$ ) was remarkable. The detected antibodies may be in part maternal antibodies, or neonate sea lions may be exposed to poxviruses within the first few weeks of birth. Poxvirus lesions were not reported in the free-ranging, nursing California sea lion pups sampled for this study. However, the neonate infections may have been mild or subclinical, or, since the pups were sampled at 2 to 4 mo of age, any clinical pox lesions may have resolved by the time of sampling. Serial samples collected during the first several weeks after birth would help clarify whether these antibodies in dependent California sea lion pups are maternally derived.

Finally, exposure to parapoxviruses appears to occur frequently in the wild. As a result, the release of captive sea lions infected with parapoxvirus into the wild should not increase the frequency of exposure of freeranging sea lions to the viruses. Therefore, the presence of pox lesions in fully rehabilitated California sea lions should not preclude their return to the wild.

Acknowledgements. This work was conducted under NMFS Permit Number 1054-1731-00 to the University of Florida. All sample collection protocols were approved by the University of Florida Institutional Animal Care and Use Committee (IACUC C403). This work was supported in part by the Batchelor Foundation, College of Veterinary Medicine, by a grant from the Florida Fish and Wildlife Conservation Commission, and by John H. Prescott Marine Mammal Rescue Assistance Grant Number NA03NMF4390410 to E.R.J. The authors thank D. Greig, L. Green and D. Duke for their assistance with this project, and R. DeLong for providing us with sera.

\section{LITERATURE CITED}

Buddle BM, Dellers RW, Schurig GG (1984) Contagious ecthyma virus-vaccination failures. Am J Vet Res 45: 263-266

Dales S, Pogo BGT (1981) Biology of poxviruses. SpringerVerlag, Vienna

Greiner M, Pfeiffer D, Smith RD (2003) Principles and practical application of the receiver-operating characteristic analysis for diagnostic tests. Prev Vet Med 45:23-41

Hadlow WJ, Cheville NF, Jellison WI (1980) Occurrence of pox in a northern fur seal on the Pribilof Islands in 1951. J Wildl Dis 16:305-312

Haig MD, McInnes C, Deane D, Reid H, Mercer A (1997) The immune and inflammatory response to orf virus. Comp Immunol Microbiol Infect Dis 20:197-204

Hastings BE, Lowenstine LJ, Gage LJ, Munn RJ (1989) An epizootic of seal pox in pinnipeds at a rehabilitation center. J Zoo Wildl Med 20:282-290

Hicks BD, Worthy GAJ (1987) Sealpox in captive grey seals (Halichoerus gyrus) and their handlers. J Wildl Dis 23:1-6

Iketani Y, Inoshima Y, Asano A, Murakami K, Shimizu S, Sentsui H (2002) Persistent parapoxvirus infection in cattle. Microbiol Immunol 46:285-291

Moss B (1996) Poxviridae: the viruses and their replication. In: Fields BN, Knipe DM, Howley PM (eds) Fields virology, 3rd edn. Lippincott-Raven Publishers, Philadelphia, p 2637-2671

Muller G, Groters S, Siebert U, Rosenberger T and 5 others (2003) Parapoxvirus infections in harbor seals (Phoca vitulina) from the German North Sea. Vet Pathol 40: 445-454

Murphy FA, Gibbs EPJ, Horzinek M, Studdert MJ (1999) Poxviridae. In: Fields B (ed) Veterinary virology, 3rd edn. Academic Press, London, p 277-292

Nettleton PF, Brebner J, Pow I, Gilray JA, Bell GD, Reid HW (1996) Tissue culture-propagated orf virus vaccine protects lambs from orf virus challenge. Vet Rec 138: $184-186$

Nollens HH, Hernandez JA, Jacobson ER, Haulena M, Gulland FMD (2005) Risk factors associated with poxvirus lesions in hospitalized California sea lions (Zalophus californianus). J Am Vet Med Assoc 227:467-473

Nollens HH, Jacobson ER, Gulland FMD, Beusse DO, Bossart GD, Hernandez JA, Klein PA, Condit RC (2006) Pathology and preliminary characterization of a parapoxvirus isolated from a California sea lion (Zalophus californianus). J Wildl Dis (in press)

Odell DK (1975) Abundance of California sea lions on San Nicolas Island, California. J Wildl Manag 39:729-736

Osterhaus ADME, Broeders HWJ, Visser IKG, Teppema JS, Vedder EJ (1990) Isolation of an orthopoxvirus from poxlike lesions of a grey seal (Halichoerus gyrus). Vet Rec 127:91-92

Osterhaus ADME, Broeders HWJ, Visser IKG, Teppema JS, Kuiken T (1994) Isolation of a parapoxvirus from pox-like lesions in grey seals. Vet Rec 135:601-602

Pye D (1990) Vaccination of sheep with cell culture grown orf virus. Aust Vet J 67:182-186

Wilson TM, Poglayen-Neuwall I (1971) Pox in South American sea lions (Otaria byronia). Can J Comp Med 35: $174-177$

Wilson TM, Cheville NF, Karstad L (1969) Seal pox. Bull Wildl Dis Assoc 5:412-418

Wilson TM, Dykes RW, Tsai KS (1972) Pox in young, captive harbor seals. J Am Vet Med Assoc 161:611-617

Submitted: August 11, 2005; Accepted: January 20, 2006

Proofs received from author(s): March 10, 2006 